\title{
Temporal Expression of PR-1 and Enhanced Mature Plant Resistance to Virus Infection Is Controlled by a Single Dominant Gene in a New Nicotiana Hybrid
}

\author{
Anthony B. Cole, ${ }^{1}$ Lóránt Király, ${ }^{2}$ Leslie C. Lane, ${ }^{3}$ B. Elizabeth Wiggins, ${ }^{1}$ Kathleen Ross, ${ }^{4}$ and \\ James E. Schoelz ${ }^{1}$ \\ ${ }^{1}$ Department of Plant Microbiology and Pathology, University of Missouri, Columbia, MO 65211, U.S.A.; ${ }^{2}$ Plant Protection \\ Institute, Hungarian Academy of Sciences, P.O. Box 102, 1525 Budapest, Hungary; ${ }^{3}$ Department of Plant Pathology, \\ University of Nebraska, Lincoln, NE 68583, U.S.A.; ${ }^{4}$ United States Department of Agriculture, Agricultural Research Service, \\ Columbia, MO 65211, U.S.A.
}

Submitted 6 February 2004. Accepted 30 April 2004.

\begin{abstract}
A new variety of Nicotiana edwardsonii, designated $N$. edwardsonii cv. Columbia, expresses pathogenesis-related (PR) proteins in a temporal manner 45 to 49 days postplanting and also exhibits enhanced resistance to Tobacco mosaic virus, Tobacco necrosis virus, and Tomato bushy stunt virus. In contrast, PR proteins were not expressed in the original N. edwardsonii variety at comparable ages but were induced after onset of a hypersensitive response to viral infection. The temporal induction of PR proteins in 'Columbia' was correlated with increases in salicylic acid and glycosylated salicylic acid. Earlier studies noted that some Nicotiana hybrids derived from interspecific crosses constitutively express PR proteins, but the genetic basis of this phenomenon had not been investigated, likely because many interspecific Nicotiana crosses are sterile. However, the close genetic relationship between $N$. edwardsonii and 'Columbia' indicated that a hybrid between these two plants might be fertile, and this proved to be true. Genetic crosses between 'Columbia' and $N$. edwardsonii demonstrated that a single, dominant gene conditioned temporal expression of $P R$ proteins and enhanced resistance. This gene was designated TPR1 (for temporal expression of PR proteins).
\end{abstract}

One of the best-characterized host resistance responses to virus infection is conditioned by the $N$ gene, a toll interleukin 1 receptor-nucleotide binding site-leucine-rich repeat (TIRNBS-LRR)-type resistance gene derived from Nicotiana glutinosa (Marathe et al. 2002; Whitham et al. 1994). The $N$ gene recognizes sequences within the helicase domain of the replicase protein of Tobacco mosaic virus (TMV) (Abbink et al. 1998; Erickson et al. 1999; Padgett and Beachy 1993), and this recognition sets in motion a cascade of plant defenses (Baker et al. 1997; Dixon et al. 1994) that limit the TMV infection to an area surrounding a small necrotic lesion in the inoculated leaf (a hypersensitive response [HR]). Host defense responses include production of reactive oxygen species (Dangl et al. 1996), activation of mitogen-activated protein kinases (Zhang and Klessig 2001), localized cell death at the initial infection

Corresponding author: J. E. Schoelz, Telephone: +1-573-882-1185; Fax: +1-573-882-0588; E-mail: schoelzj@ missouri.edu

Current address of A. Cole: The Samuel Roberts Noble Foundation, Ardmore, OK, U.S.A. site (Mittler et al. 1996), and induction of salicylic acid with a subsequent increase in PR proteins (Bol et al. 1990).

Through the years, at least one anomaly has been noted concerning $N$ gene-mediated resistance that has not been widely recognized; some Nicotiana species that contain the $N$ gene respond with an initial HR but fail to contain the virus, permitting systemic invasion. This systemic movement of TMV occurs at temperatures well below the threshold temperature for inactivation of the $N$ gene. Development of systemic necrosis in the presence of the $N$ gene was actually noted by Holmes (1954) and has also been investigated by other researchers (Dijkstra et al. 1977; Zaitlin 1962). Zaitlin (1962) characterized systemic movement of TMV in N. glutinosa and N. tabacum cv. Xanthinc and concluded that the necrotic reaction could spread through vascular bundles in two ways, a relatively slow cell-tocell manner and, more rapidly, through the phloem. This phenomenon is not due to selection of a TMV mutant, as only one isolate has been found to overcome $N$ gene-mediated resistance (Padgett and Beachy 1993). Furthermore TMV recovered from systemically infected $N$. glutinosa did not exhibit an enhanced ability to infect $N$. glutinosa in subsequent inoculations (Zaitlin 1962). Consequently, it is considered that systemic movement of TMV in $\mathrm{N}$-gene plants is due to effects on the host side of the interaction.

It is not known whether the failure of $N$ gene-mediated resistance in some Nicotiana species is conditioned by the genetic background of the plant (McKinney and Clayton 1945 ) or by defects in the $N$ gene itself, although experimental evidence indicates either hypothesis is plausible. For example, systemic necrosis due to movement of TMV in $\mathrm{N}$-gene plants occurs if some component of the plant defense response is compromised. N. tabacum cv. Xanthi nc tobacco, which expresses a $N a h G$ transgene, is unable to accumulate salicylic acid and, consequently, PR proteins (Delaney et al. 1994). In addition, antioxidant enzyme activity is decreased in NahG tobacco (Király et al. 2002). The impairment in these defenses results in development of necrotic symptoms that extend into the stem. On the other hand, alterations in expression patterns of the $N$ gene may also lead to systemic necrosis (DineshKumar and Baker 2000). Thus, either mechanism could conceivably explain failure of $N$ gene-mediated resistance in some Nicotiana species.

Another unusual feature of the Nicotiana genus is the tendency of some hybrids to constitutively express pathogenesis-related (PR) proteins, a phenomenon first noted in a cross 
between $N$. glutinosa and $N$. debneyi (Ahl and Gianinazzi 1982). The hybrids also exhibited enhanced resistance to virus infection, characterized by reduction in lesion size in response to inoculation with either TMV or Tobacco necrosis virus (TNV). Later studies have indicated that virus resistance can be correlated with increases in salicylic acid (Chivasa et al. 1997; Murphy et al. 1999) and is not due to increases in levels of PR proteins themselves (Carr et al. 1989; Cutt et al. 1989; Dumas and Gianinazzi 1986; Linthorst et al. 1989). However, the genetic basis for constitutive expression of PR proteins is unknown, because many Nicotiana interspecific crosses are sterile. Presumably though, both parental species contribute one or more genes that result in constitutive expression of PR proteins.

In this paper, we describe two varieties of Nicotiana edwardsonii that both contain the $N$ gene but respond very dif- ferently to TMV infection as well as to other viruses, such as TNV and Tomato bushy stunt virus (TBSV). N. edwardsonii is an amphidiploid derived from a cross between $N$. glutinosa and $N$. clevelandii. Although the N. edwardsonii genome contains a copy of the $N$ gene (Christie 1969), this host should be considered susceptible to TMV. In contrast, $N$. edwardsonii cv. Columbia is also derived from N. glutinosa and N. clevelandii (Cole et al. 2001), but it is resistant to TMV infection. Furthermore, 'Columbia' can be distinguished from the original $N$. edwardsonii, because PR proteins are expressed in 'Columbia' in a temporal manner. Because of the close genetic relationship of the two varieties of $N$. edwardsonii, it has been possible to examine, for the first time, inheritance of spontaneous expression of PR proteins and enhancement in virus resistance that occurs in some Nicotiana hybrids.
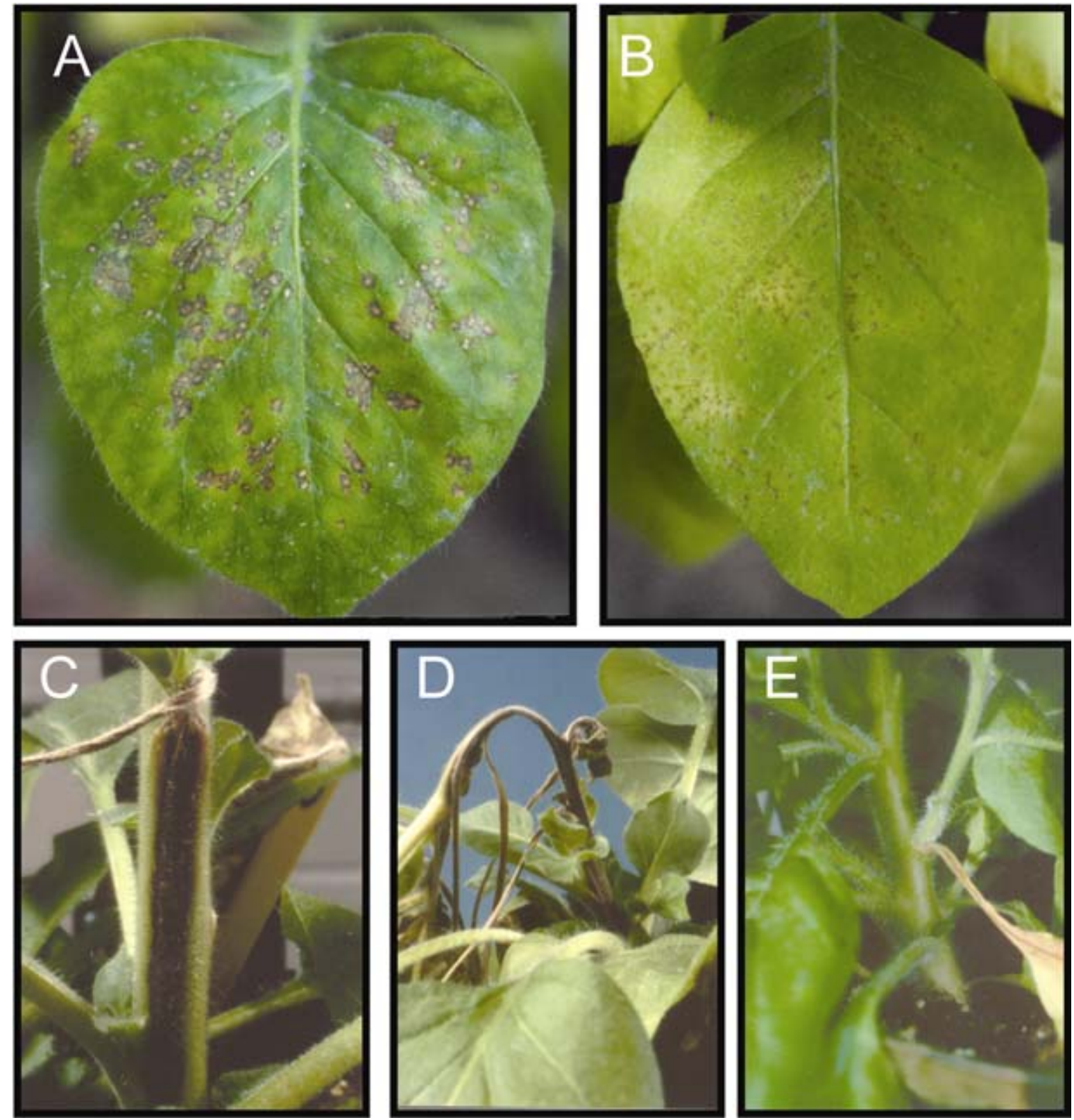

Fig. 1. Comparison of the systemic movement of Tobacco mosaic virus (TMV) in Nicotiana edwardsonii and N. edwardsonii cv. Columbia. A, Necrotic local lesions induced by TMV in a N. edwardsonii leaf. B, Necrotic local lesions induced by TMV in a 'Columbia' leaf. C, Necrosis associated with the systemic movement of TMV in N. edwardsonii from the petiole of the inoculated leaf into the vascular tissue. D, Systemic movement of TMV in $N$. edwardsonii is illustrated by the advancement of necrosis in the vascular tissue of $N$. edwardsonii. At this stage, the necrosis has girdled the stem, resulting in death of the meristem. E, Senescence of a 'Columbia' leaf that had been inoculated with TMV. 


\section{RESULTS}

The resistance response of $N$. edwardsonii to TMV infection is compromised, whereas 'Columbia' exhibits strong resistance.

N. edwardsonii responds to infection by TMV with HR, but the virus does not remain limited to the inoculated leaf. The movement of TMV into the petiole and stem tissues of mature N. edwardsonii plants was easily visualized as early as 10 days postinoculation, as TMV killed cells as it advanced (Fig. 1C). Enzyme-linked immunosorbent assays (ELISA) confirmed that upper necrotic tissues contained TMV virions (data not shown). Eventually the stem became girdled, and the top of the plant died (Fig. 1D). It is well-documented that the $N$ gene is temperature-sensitive (Samuel 1931; Weststeijn 1981). To investigate whether ambient temperatures had exceeded the threshold for $N$-gene inactivation, greenhouse temperatures were monitored with a data recorder. The average daily high temperature never exceeded $23^{\circ} \mathrm{C}$ (data not shown), which is well below the $28^{\circ} \mathrm{C}$ threshold for $\mathrm{N}$-gene inactivation.

In contrast to $N$. edwardsonii, mature 'Columbia' plants did not develop systemic TMV infections. TMV induced HR in 'Columbia' leaves and then spread to induce premature leaf senescence. Typically, the spread of the TMV infection could be visualized as yellowing and collapse of the petioles (Fig. $1 \mathrm{E})$. However, virus infections did not spread beyond the petiole, as the infected leaf would senesce and drop from the plant. In contrast, inoculated $N$. edwardsonii leaves tended to remain on the plant, even after the leaf and petiole had turned completely necrotic (Fig. 1C). The premature senescence elicited in 'Columbia' leaves in response to TMV infection may be a part of the explanation why TMV was unable to reach the main stem of the plant.

To investigate whether the $N$ gene of $N$. edwardsonii might contain a mutation that would cause it to be defective, total DNA was isolated from $N$. edwardsonii plants, and in a series



Fig. 2. Expression of PR-1 protein in Nicotiana edwardsonii cv. Columbia is temporally regulated. Total protein extracts from $N$. edwardsonii (N.e.) and 'Columbia' (N.e.C.) were obtained at 42, 49, and 56 days postplanting (dpp) and were probed with antibodies to PR-1. The positive control for PR-1 protein expression was $N$. edwardsonii inoculated with Cauliflower mosaic virus W260, an interaction that results in a hypersensitive response (lane 7). of overlapping polymerase chain reactions (PCR), its $N$ gene was amplified and sequenced. We found nine differences within the 6,731 nucleotides sequenced that distinguished the $N$ gene of $N$. edwardsonii from the published sequence (Whitham et al. 1994) (Table 1). Of these differences, one occurred in exon 1 but was silent, six occurred in introns, and two differences in exon 4 resulted in amino acid changes. To assess the significance of these coding changes, the relevant portions of the $N$ genes from $N$. glutinosa and 'Columbia' were also amplified and sequenced. At each of the nine nucleotide positions, the $N$-gene sequences agreed with the $N$. edwardsonii sequence. Since neither $N$. glutinosa nor 'Columbia' exhibit the same degree of susceptibility to TMV as does $N$. edwardsonii, it is unlikely that the systemic movement of TMV in $N$. edwardsonii could be due to a defect in the coding sequence of the $N$ gene.

PR proteins are temporally expressed in 'Columbia' plants.

Although N. edwardsonii and 'Columbia' are closely related genetically, they responded very differently to TMV infection. A possible explanation for this difference is that plant defenses might be spontaneously turned on in 'Columbia'. For example, some interspecific Nicotiana hybrids constitutively express PR proteins and, consequently, are more resistant to TMV infection (Ahl and Gianinazzi 1982). To determine if PR proteins were expressed in 'Columbia' plants, total proteins were extracted from healthy leaves of $N$. edwardsonii and 'Columbia' at weekly intervals, beginning at 7 days postplanting (dpp) and ending at $56 \mathrm{dpp}$. Protein extracts were then probed with PR-1 antibody by Western blotting.

Neither N. edwardsonii nor 'Columbia' plants younger than 42 dpp expressed PR-1 protein. Beginning at 49 dpp, PR-1 protein appeared in healthy 'Columbia' leaves (Fig. 2). In contrast, healthy N. edwardsonii leaves did not express PR-1 protein at any timepoint, although $N$. edwardsonii can express PR-1 protein during a $\mathrm{HR}$ to Cauliflower mosaic virus (CaMV) W260 (Fig. 2, lane 7). This temporal induction of PR1 protein between 42 and 49 dpp in 'Columbia' plants was very reproducible.

Environmental stresses can also induce PR proteins. However, the $N$. edwardsonii and 'Columbia' plants were grown adjacent to each other, demonstrating that greenhouse conditions were not responsible for the induction of PR proteins in the 'Columbia' plants. Although some Nicotiana hybrids constitutively express PR proteins (Ahl and Gianinazzi 1982), to our knowledge, the response of 'Columbia' is the first example of temporal induction of PR proteins in a Nicotiana hybrid.

\section{The enhanced resistance of 'Columbia' is correlated with the onset of PR protein induction and is not limited to TMV infections.}

To investigate whether 'Columbia' plants become more resistant to TMV infection after the onset of PR protein expression,

Table 1. Sequence comparison of the $N$ gene derived from different Nicotiana species

\begin{tabular}{|c|c|c|c|c|c|c|c|}
\hline Base & Location & Published sequence $^{a}$ & N. edwardsonii ${ }^{\mathrm{b}}$ & N. glutinosa & 'Columbia' & Line 24 & Amino acid change? \\
\hline 513 & Exon 1 & $\mathrm{C}$ & A & A & $\mathrm{A}$ & A & No \\
\hline 1963 & Intron 3 & A & $\mathrm{C}$ & $\mathrm{C}$ & $\mathrm{C}$ & $\mathrm{C}$ & \\
\hline 1964 & Intron 3 & $\mathrm{C}$ & A & A & A & A & \\
\hline 2327 & Intron 3 & $\mathrm{~A}$ & $\mathrm{C}$ & $\mathrm{C}$ & $\mathrm{C}$ & $\mathrm{C}$ & \\
\hline 2457 & Intron 3 & $\mathrm{C}$ & A & A & A & A & \\
\hline 3037 & Intron 4 & - & $+\mathrm{T}$ & $+\mathrm{T}$ & $+\mathrm{T}$ & $+\mathrm{T}$ & \\
\hline 4052 & Intron 4 & - & $+\mathrm{C}$ & $+\mathrm{C}$ & $+\mathrm{C}$ & $+\mathrm{C}$ & \\
\hline 5500 & Exon 4 & $\mathrm{G}$ & $\mathrm{T}$ & $\mathrm{T}$ & $\mathrm{T}$ & $\mathrm{T}$ & Yes E to D \\
\hline 5699 & Exon 4 & $\mathrm{~T}$ & $\mathrm{G}$ & $\mathrm{G}$ & $\mathrm{G}$ & $\mathrm{G}$ & Yes $\mathrm{Y}$ to $\mathrm{D}$ \\
\hline
\end{tabular}

${ }^{a} N$ gene sequence determined from $N$. tabacum by Whitham and associates (1994).

$\mathrm{b}$ The + sign indicates the addition of a nucleotide. 
we compared the response of $N$. edwardsonii and 'Columbia' plants inoculated at $35 \mathrm{dpp}$ with those inoculated at $60 \mathrm{dpp}$. All plants developed necrotic local lesions by 2 days postinoculation (dpi). As illustrated in Figure 3A, there was no significant difference in lesion size between the two varieties, when they were inoculated at $35 \mathrm{dpp}$. However, in those plants inoculated at $60 \mathrm{dpp}$, there was a significant difference in lesion size (Fig. $3 \mathrm{~B})$. The necrotic local lesions on the 'Columbia' variety were smaller than lesions on the inoculated leaves of the original $N$. edwardsonii (compare Fig. 1A and B). Thus, a reduced lesion size correlated with temporal expression of PR proteins.

To determine if temporal expression of PR proteins correlated with limitations in systemic movement of TMV, the TMV-inoculated plants used in the analysis of lesion size were monitored for 25 days after inoculation. Systemic movement was scored as development of necrosis in the stem at the base of the petiole of the inoculated leaf. In the case of plants inoculated at an age of $35 \mathrm{dpp}$, stem necrosis and, thus, virus movement was evident in both varieties at 10 dpi (Fig. 3C), although a greater percentage of $\mathrm{N}$. edwardsonii plants developed vascular stem necrosis than 'Columbia' plants. Interestingly, the maximum for 'Columbia' was attained at 15 dpi. At this point in the test, plants were 50 days old and temporal expression of PR proteins would have begun. In the case of plants inoculated at $60 \mathrm{dpp}$, all N. edwardsonii plants exhibited stem necrosis by 25 dpi (Fig. 3D). In contrast, only $4 \%$ of N. edwardsonii cv. Columbia developed stem necrosis in the same time frame (Fig. 3D). This study indicated that enhanced resistance to systemic movement of TMV correlated with induction of PR proteins in 'Columbia' plants.

Christie (1969) had noted that TMV could kill the apical meristem of $N$. edwardsonii. Of the young $N$. edwardsonii
35 DPP


60 DPP
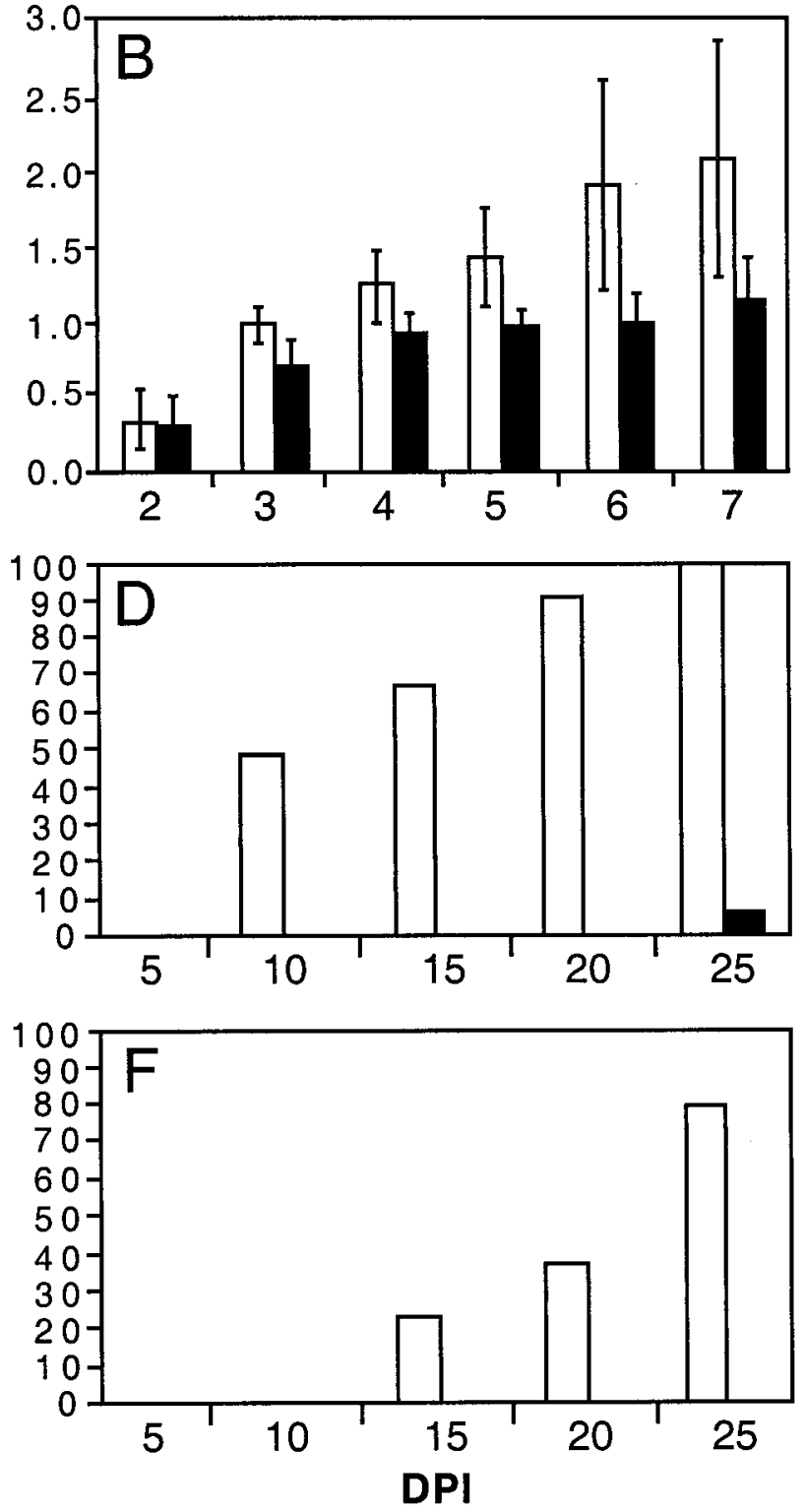

Fig. 3. Comparison of the development of Tobacco mosaic virus (TMV) infections in Nicotiana edwardsonii and N. edwardsonii cv. Columbia plants inoculated at either 35 or 60 days postplanting (dpp). The white bars represent TMV infections in $N$. edwardsonii, whereas the black bars represent TMV infections in 'Columbia'. A, and B, Comparison of necrotic lesion sizes induced by TMV on the leaves of the two varieties, inoculated at 35 or 60 dpp. C, and D, Movement of TMV into the stem of $N$. edwardsonii and 'Columbia' following inoculation at 35 or 60 dpp. The observation at each timepoint represents the percentage of plants that exhibited stem necrosis. E, and F, Death of the apical meristem induced by TMV in $N$. edwardsonii and 'Columbia' plants inoculated at 35 or $60 \mathrm{dpp}$. The observation at each timepoint represents the percentage of plants in which the apical meristem has died. 
plants (35 dpp) inoculated with TMV, nearly $28 \%$ developed systemic necrosis by 25 dpi that was severe enough to kill the apical meristem (Fig. 3E). Killing of the apical meristem of $N$. edwardsonii was even more pronounced in the older N. edwardsonii plants (60 dpp) (Fig. 3F). On average, $80 \%$ of the apical meristems of these plants died from girdling induced by systemic necrosis (Figs. 1B and 3F). In contrast, none of the api-


Fig. 4. Comparion of local lesions induced by Tobacco necrosis virus and Tomato bushy stunt virus in Nicotiana edwardsonii and N. edwardsonii cv. Columbia. A, The N. edwardsonii leaf is positioned on the left, and the 'Columbia' leaf is on the right. B, The 'Columbia' leaf is positioned on the left, and the $N$. edwardsonii leaf on the right. cal meristems of either young (35 dpp) or old (60 dpp) 'Columbia' plants died. These results provided further evidence that the Columbia cultivar restricts TMV movement. They also showed that even young 'Columbia' plants were more resistant to TMV infection than young N. edwardsonii plants. However, as 'Columbia' plants aged, the difference in susceptibility to TMV between them and the original N. edwardsonii increased.

To determine if 'Columbia' plants display enhanced resistance to viruses other than TMV, we inoculated 'Columbia' and $N$. edwardsonii with TNV and TBSV. These plants were 50 to 80 days old at the time of inoculation, an age when 'Columbia' plants express PR proteins. All plants inoculated with TNV developed necrotic local lesions by 3 dpi. As illustrated in Figure 4A, there were significant differences in lesion numbers between the varieties. The number of necrotic local lesions following TNV inoculation was severalfold less on the 'Columbia' leaves than on inoculated leaves of the original $N$. edwardsonii, although the difference became less pronounced by 5 dpi. In addition, lesion size in 'Columbia' plants was about half or less than that in N. edwardsonii. Plants were kept for at least $30 \mathrm{dpi}$, and within this period TNV remained localized in the inoculated leaves (data not shown). A similar enhancement in resistance was observed with TBSV, as lesions were considerably smaller in 'Columbia' leaves relative to N. edwardsonii (Fig. 4B). Thus, 'Columbia' displayed generally enhanced resistance to virus infections. The enhancement in resistance to viruses that were unrelated to TMV indicated that this response was not directly mediated by the $N$ gene.

\section{Enhanced virus resistance and induction of $P R$ proteins is associated with an increase in salicylic acid.}

Salicylic acid (SA) is an endogenous signal involved in resistance to virus infections and induction of $P R-1$ gene expression (Klessig and Malamy 1994; Ryals et al. 1996; Sticher et al. 1997). Levels of free SA and its conjugated forms increase during TMV infection of resistant tobacco that contains the $N$ gene in parallel with the development of HR. These changes ultimately increase resistance to subsequent infections and induce PR-1 proteins (Hennig et al. 1993; Malamy et al. 1990, 1992).

To determine whether increased levels of salicylic acid are correlated with enhanced virus resistance and PR-1 induction displayed by 'Columbia', we assayed levels of free and conjugated SA in 'Columbia' and N. edwardsonii in 90-day-old

Table 2. Comparison of free and conjugated salicylic acid (SA) levels in Nicotiana edwardsonii and N. edwardsonii cv. Columbia at 90 days postplanting

\begin{tabular}{llllrr}
\hline Form if SA & N.e./mock & N.e.C/mock & N.e./TNV & N.e.C/TNV & N.e./TMV \\
\hline Free SA & $0.12 \pm 0.03$ & $0.21 \pm 0.08$ & $0.16 \pm 0.02$ & $0.36 \pm 0.07$ & $5.76 \pm 1.93$ \\
Conjugated SA & $0.15 \pm 0.03$ & $1.19 \pm 0.75$ & $0.15 \pm 0.03$ & $2.36 \pm 1.22$ & $2.72 \pm 2.12$ \\
\hline
\end{tabular}

${ }^{a}$ N.e. $=$ N. edwardsonii $;$ N.e.C $=$ N. edwardsonii $\mathrm{cv}$. Columbia; TNV = Tobacco necrosis virus; TMV = Tobacco mosaic virus; measurement is $\mu \mathrm{g} / \mathrm{g}$ fresh weight \pm standard deviation.

Table 3. Temporal expression of PR-1 protein in N. edwardsonii and N. edwardsonii cv. Columbia and their subsequent progeny ${ }^{\mathrm{a}}$

\begin{tabular}{|c|c|c|c|c|c|}
\hline Plant & PR-1 expression & No PR-1 expression & Expected ratio & Observed ratio & $\mathrm{Chi}^{2}(0.05 ; 1)$ \\
\hline N. edwardsonii & 0 & 20 & & & \\
\hline N. edwadsonii cv. Columbia & 20 & 0 & & & \\
\hline F1 (N.e. $\times$ N.e.C.) & 47 & 0 & $1: 0$ & $1: 0$ & 0 \\
\hline B1 $($ F1 $\times$ N.e. $)$ & 30 & 6 & $1: 1$ & $5: 1$ & 16 \\
\hline B2 $\left(\mathrm{B} 1^{\mathrm{b}} \times\right.$ N.e. $)$ & 52 & 44 & $1: 1$ & $1.2: 1$ & 0.67 \\
\hline B2 Self (F2) & 17 & 5 & $3: 1$ & $3.4: 1$ & 0.06 \\
\hline B3 $($ B2 $\times$ N.e. $)$ & 11 & 11 & $1: 1$ & $1: 1$ & 0 \\
\hline B3 Self (F3) & 43 & 13 & $3: 1$ & $3.6: 1$ & 0.36 \\
\hline
\end{tabular}

${ }^{\text {a }}$ Temporal expression of PR-1 protein was determined at 60 days postplanting by Western blotting, using a PR-1 monoclonal antibody. Plants were scored for expression or nonexpression. N.e. $=$ N. edwardsonii and N.e.C. = N. edwardsonii cv. Columbia.

b The backcross 1, 2, and 3 parents (B1, B2, and B3) were selected for temporal expression of PR-1 protein. 
plants that were either inoculated with TNV, TMV, or mockinoculated. In mock-inoculated plants, the level of free SA was slightly higher in 'Columbia' than in N. edwardsonii, whereas conjugated SA was nearly eight times higher in 'Columbia' than in N. edwardsonii (Table 2). The differences between 'Columbia' and N. edwardsonii became more pronounced after infection with either TNV or TMV. Free SA levels were approximately twofold higher in 'Columbia' relative to $N$. edwardsonii after inoculation with either virus. However, the most dramatic differences could be seen in the levels of conjugated SA after inoculation with either virus. After inoculation with TNV, the level of conjugated SA was 15-fold higher in 'Columbia' leaves than in N. edwardsonii leaves (Table 2). Similarly, there was a 12-fold difference in conjugated SA levels between 'Columbia' and N. edwardsonii leaves after inoculation with TMV. The majority of the conjugated, acid hydrolyzable SA fraction we detected probably represents SA glucoside (SAG) (Hennig et al. 1993; Malamy et al. 1992). Although SAG is considered to be biologically inactive (Hennig et al. 1993), its hydrolysis to SA may require as little as $2 \mathrm{~h}$. Therefore, SAG could be a storage form to be rapidly converted to SA after pathogen infection. The increases in SA and conjugated SA levels in 'Columbia' indicated that these plants were primed to resist pathogen infections before inoculation and, consequently, could respond more strongly after virus infection.

\section{Temporal expression of PR-1 protein is conditioned by a single, dominant gene.}

Although earlier papers noted that some Nicotiana hybrids derived from interspecific crosses constitutively express PR proteins (Ahl and Gianinazzi 1982), the genetic basis of this phenomenon had not been investigated, likely because many interspecific Nicotiana crosses are sterile. However, the close genetic relationship between $N$. edwardsonii and the 'Colum-

$\mathrm{Ne} /$

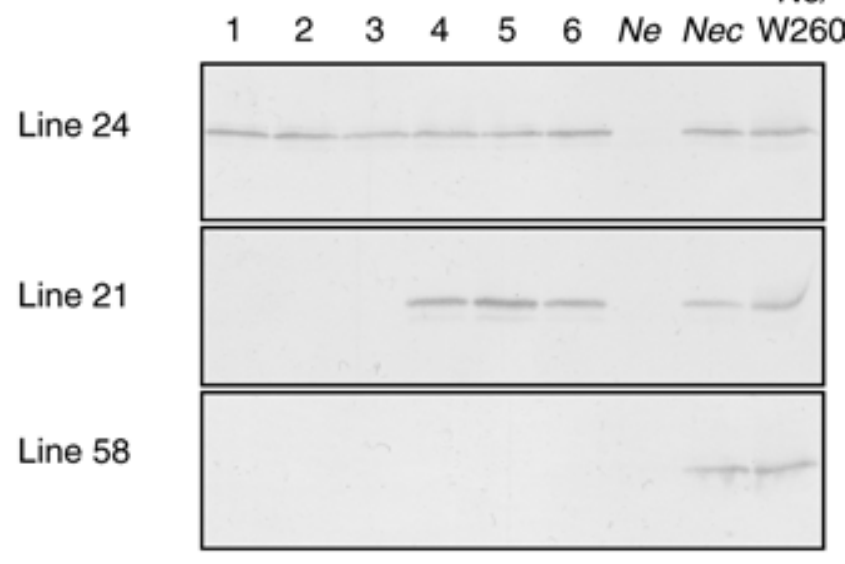

Fig. 5. Identification of F4 lines that are homozygous for the temporal expression of PR-1 protein. Total protein extracts were obtained from selected F4 lines, Nicotiana edwardsonii (N.e.) plants, and N. edwardsonii cv. Columbia (N.e.C.) plants. The positive control for PR-1 protein expression was $N$. edwardsonii inoculated with Cauliflower mosaic virus W260 (N.e. W260), an interaction that results in a hypersensitive response. bia' variety indicated that a hybrid between these two plants might be fertile. To evaluate inheritance of one or more genes that condition temporal PR protein expression, we crossed 'Columbia' with $N$. edwardsonii and evaluated progeny for PR-1 protein expression in healthy leaves at 60 dpp. All F1 progeny expressed detectable PR-1 protein at $60 \mathrm{dpp}$ (Table 3 ), which suggested that a dominant gene conditioned temporal expression of PR-1.

To further investigate inheritance of PR protein expression, we backcrossed the F1 plants with the original $N$. edwardsonii. Of the 36 B1 plants examined, 30 expressed PR-1, resulting in a 5:1 segregation of expressors to nonexpressors (Table 3). This atypical ratio might reflect unequal segregation of chromosomes from the two parents, as $N$. edwardsonii has 68 chromosomes (Christie and Hall 1979), while 'Columbia' has 72 chromosomes (Cole et al. 2001). To determine if the segregation ratio could be stabilized, hybrids were backcrossed two additional times with $N$. edwardsonii.

The near 1:1 segregation of PR-1 expression observed in the B2 population as well as the 1:1 ratio observed in the subsequent B3 population supported the hypothesis that temporal expression was a heritable, dominant trait (Table 3). The segregation of temporal expressors to nonexpressors in the F2 and F3 populations at near 3:1 ratios verified that a single, dominant gene conditions temporal expression of PR-1. This gene was designated TPRI (for temporal expression of PR proteins).

\section{Identification}

of homozygous expressors and nonexpressors of PR-1.

From the 43 expressors in the $\mathrm{F} 3$ population, 14 plants were selected, in an attempt to identify homozygous temporal expressors of PR-1. In addition, two of the five nonexpressors from the F3 population were also selected to identify homozygous nonexpressors. The individual plants were selfed, and 20 plants from each of the subsequent F4 lines were evaluated for expres-

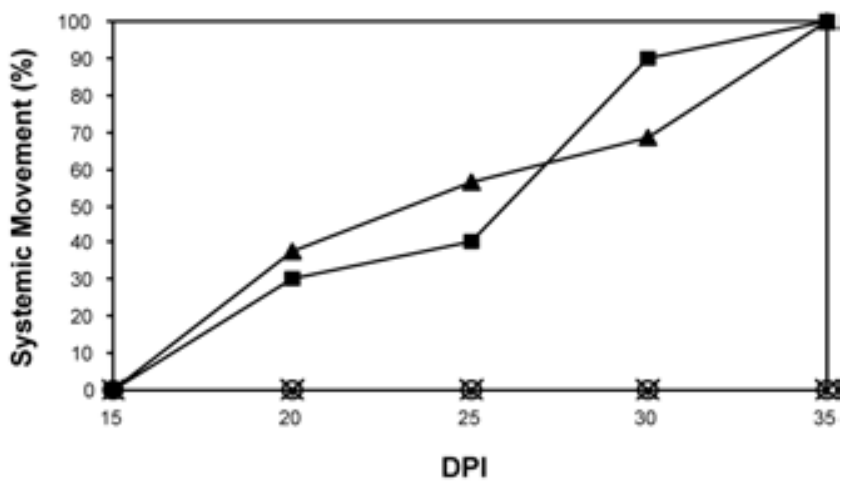

Fig. 6. Comparison of the development of Tobacco mosaic virus infections in the F4 lines 24 and 58 as well as in Nicotiana edwardsonii and $N$. edwardsonii cv. Columbia plants, inoculated at either 35 or 60 days postplanting. The graph illustrates the percentage of plants that exhibited any stem necrosis during the period from 15 to 35 days postinoculation (dpi). $N$. edwardsonii is represented by filled triangles, F4 line 58 (nonexpressor line) by filled squares, 'Columbia' by open circles, and F4 line 24 (temporal expressor line) by Xs.

Table 4. Comparison of the sizes of Tobacco mosaic virus-induced lesions on the inoculated leaves of Nicotiana species

\begin{tabular}{lcc}
\hline Host & 5 Days postinoculation & 8 Days postinoculation \\
\hline N. edwardsonii & $0.86 \pm 0.15(20)^{\mathrm{a}}$ & $1.11 \pm 0.17(20)$ \\
F4 Line 58 & $0.89 \pm 0.13(20)$ & $1.09 \pm 0.12(20)$ \\
F4 line 24 & $0.53 \pm 0.19(20)$ & $0.80 \pm 0.13(20)$ \\
N. edwardsonii cv. Columbia & $0.72 \pm 0.17(20)$ & $0.94 \pm 0.10(20)$ \\
\hline
\end{tabular}

${ }^{a}$ Values are expressed as lesion diameters in $\mathrm{mm}$. The number of lesions measured is presented in parentheses. 
sion of PR-1 at $60 \mathrm{dpp}$. In this manner, the F4 line 24 was identified as a homozygous expressor of PR-1, and the F4 line 58 was found to be a homozygous nonexpressor (Fig. 5). The identification of several heterozygous lines, represented by the F4 line 21 in Figure 5, validated this method for selection of homozygous lines. Line 24 was determined to have 68 chromosomes (data not shown), which demonstrated that TPRI had been introgressed successfully from 'Columbia' to $N$. edwardsonii.

Interestingly, expressors were shorter than nonexpressors (data not shown), a trait that has been associated with expression of SA. In fact, the homozygous nonexpressor lines were comparable in height to the original $N$. edwardsonii, whereas the homozygous expressor line was uniformly shorter than $N$. edwardsonii. Heterozygous lines were a mixture of short and tall plants, and this difference in height correlated with temporal PR-1 expression.

Our sequence analysis of the $N$ gene from $N$. edwardsonii and 'Columbia' had revealed nine differences with the published sequence (Table 1). To ensure that the $N$ gene of line 24 agreed with the sequence derived from $N$. edwardsonii and 'Columbia', the relevant portions of the $N$ gene from line 24 were also amplified and sequenced. At each of the nine nucleotide positions, the $N$-gene sequences agreed with the $N$. edwardsonii sequence. This provided further evidence that the coding sequence of the $N$ gene was not responsible for the temporal expression of PR proteins.

\section{The homozygous expressor of PR-1 protein is more resistant to TMV than is the homozygous nonexpressor.}

To confirm continued association of PR protein expression and TMV resistance in the F4 lines, 20 plants each of $N$. edwardsonii, 'Columbia', the homozygous expressor F4 line 24, and the homozygous nonexpressor F4 line 58 were inoculated with TMV at $60 \mathrm{dpp}$. The diameters of 20 lesions per cultivar were measured daily, until individual lesions could no longer be discerned. As shown in Table 4, necrotic lesions induced on the inoculated leaves of F4 line 24 were smaller than those on either F4 line 58 and $N$. edwardsonii but were the same size as those on 'Columbia'.

These plants were maintained for $35 \mathrm{dpi}$ and were monitored daily for evidence of systemic TMV movement. As shown in Figure 6, TMV moved systemically in line 58 but not in line 24 . By 35 dpi, all N. edwardsonii and F4 line 58 plants had developed vascular necrosis, indicative of systemic TMV movement. Since line 58 responded to TMV infection with HR, it demonstrated that it had retained the $N$ gene and that TPR-1 segregates independently from the $N$ gene. In contrast, TMV was unable to move systemically in either 'Columbia' or in F4 line 24 plants.



Fig. 7. Comparison of flowering times of the F3 plants $(n=43)$ that temporally expressed PR-1 (open squares) to the flowering times of Nicotiana edwardsonii (X) and N. edwardsonii cv. Columbia (open triangles). The graph illustrates the percentage of plants that had begun to flower between 45 and 65 days postplanting.
This test provided further evidence that the enhanced resistance to TMV was linked to temporal PR-1 expression.

\section{Temporal expression of PR-1 is not associated with flowering.}

Flowering induces expression of PR proteins in leaves of healthy tobacco plants and in sepals of tobacco flowers (Fraser 1981; Lotan et al. 1989). Since 'Columbia' begins to flower approximately five days earlier than $N$. edwardsonii, the onset of flowering might be responsible for the induction of PR-1 protein expression in 'Columbia' plants. To determine whether the temporal PR-1 expression observed in 'Columbia' and its progeny was associated with flowering, we compared flowering times of $N$. edwardsonii, 'Columbia', and the PR-1 expressors selected from the F3 backcross population. As illustrated in Figure 7, there was no difference in flowering times between the F3 expressors and $N$. edwardsonii, demonstrating that early onset of flowering and PR-1 protein expression in 'Columbia' leaves are likely controlled by different genes.

\section{DISCUSSION}

It had previously been found that an interspecific hybrid between $N$. glutinosa and $N$. debneyi constitutively expressed PR-1 protein and had an enhanced level of resistance to TMV (Ahl and Gianinazzi 1982). The genetic basis of this phenomenon was not characterized in that paper, but the authors speculated that "it is possible that the interaction of their two foreign genomes provokes a permanent accumulation of" PR proteins.

In our paper, we found that PR-1 protein is temporally expressed in N. edwardsonii cv. Columbia, an interspecific hybrid between $N$. glutinosa and $N$. clevelandii. Interestingly, PR-1 protein was not temporally expressed in the original N. edwardsonii, although it could be induced after the onset of HR. The close genetic relationship between $N$. edwardsonii and 'Columbia' allowed us to examine, for the first time, the inheritance of temporal resistance in interspecific crosses, and our evidence indicates that a single dominant gene is responsible for the difference in temporal expression of PR proteins between the two plants. The effects of TPR- 1 can be observed in both inoculated and upper, noninoculated leaves. TPR-1 contributed to a reduction in lesion size in the inoculated leaves and was also responsible for blocking systemic movement of TMV, when introgressed into $N$. edwardsonii (Fig. 6). At this point, we do not know if TPRI is derived from the $N$. glutinosa parent or the $N$. clevelandii parent. It is likely, though, that both $N$. glutinosa and $N$. clevelandii contributed genes to condition temporal expression in 'Columbia' and that the original N. edwardsonii received genes from only one of the parents. Since 'Columbia' contains two pairs of chromosomes that are missing in the original N. edwardsonii (Cole et al. 2001), it is also likely that TPRI can be localized to one of these two pairs.

Ahl and Gianinazzi (1982) reported constitutive PR protein expression, whereas we found that PR-1 expression was temporally regulated in 'Columbia', beginning about 45 days after planting. This discrepancy may reflect differences in experimental analyses rather than true biological differences, as PR1 protein expression was not examined in the $N$. glutinosa $\times N$. debneyi hybrid until two months after planting (Ahl and Gianinazzi 1982), well after the threshold for temporal induction in 'Columbia' plants. Consequently, PR proteins may be temporally expressed in the $N$. glutinosa $\times N$. debneyi hybrid as well as in 'Columbia'.

There were no apparent phenotypic changes in 'Columbia' plants to indicate what happens around $45 \mathrm{dpp}$ to induce SA and PR protein expression. There is, however, an intriguing parallel to the induction of SA in N. edwardsonii. The N. edwardsonii 
genome contains multiple copies of the plant pararetrovirus Tobacco vein clearing virus (TVCV), and this virus is released into an episomal form 5 to 6 weeks after transplanting (Lockhart et al. 2000). In an analysis of the two parents of N. edwardsonii, TVCV appeared as an integrated form only in N. glutinosa plants, and it is absent in the $N$. clevelandii genome. It is speculated that the integrated form may be activated by the hybridization of the two parental genomes. Thus, hybridization of $N$. glutinosa with $N$. clevelandii results in mobilization of TVCV as well as induction of SA. The difference between the two phenomena is that SA is only induced in 'Columbia', whereas TVCV is activated in N. edwardsonii as well.

Developmental resistance to pathogens is a phenomenon that has not been well-characterized. Leisner and coworkers (1993) characterized a form of developmental resistance in Arabidopsis to CaMV that was related to sink-source relationships. As leaves mature, they change from acting as a sink for photoassimilates and virus to serving as a source. Leaves that mature before becoming infected tend to remain uninfected, because the virus movement into that leaf is impeded. Thus, as Arabidopsis plants age, an increasing proportion of leaves become resistant to virus infection. This type of developmental resistance would likely differ from $T P R 1$, as it would not be based on induction of SA-dependent defense pathways.

Developmental resistance in $N$. tabacum has been examined in response to Phytophthora parasitica, and two components in this defense response have been characterized (Hugot et al. 1999). One component targeted infection effectiveness and was SA-independent. A second component, which restricted fungal expansion, was correlated with induction of PR proteins after the onset of flowering at 80 to $85 \mathrm{dpp}$. In contrast to their study, we found that induction of plant defenses in 'Columbia' was independent of flowering, as there was no correlation between the induction of PR 1 and the timing of flowering (Fig. 7). Furthermore, PR1 protein was induced at a much earlier time in 'Columbia' (45 dpp) than in $N$. tabacum ( 80 to $85 \mathrm{dpp}$ ). Finally, the function of TPRl was only revealed in an interspecific cross between two Nicotiana species. Consequently, it is likely that TPRl is distinct from the plant defenses characterized in Hugot and associates (1999).

Several Arabidopsis mutant genes have been characterized that condition constitutive PR protein expression. These mutants include cpr (Bowling et al. 1994; Yoshioka et al. 2001), cim (Ryals et al. 1996), acd (Greenberg et al. 1994; Rate et al. 1999), ssi (Shah et al. 1999; Shirano et al. 2002), and $l s d$ (Dietrich et al. 1994). Interestingly, the mutant ssi4 has been shown to be a TIR-NBS-LRR class of resistance proteins (Shirano et al. 2002), which shows that mutations within $R$ genes can lead to upregulation of SA levels. TPRI could be homologous to one of these types of genes, but differences in regulation of expression and associated phenotypes are worth noting. For example, TPRl conditions temporal expression of PR1 protein, whereas the other genes condition constitutive expression of PR proteins. It could be that expression of TPR1 is itself turned on around $45 \mathrm{dpp}$ and that this leads to the induction of SA and PR proteins. Furthermore, many of the Arabidopsis mutants spontaneously develop cell death, whereas no lesions are apparent on the 'Columbia' plants. As we learn more about the genome organization of Nicotiana spp., it should be possible to locate and clone TPR1. This will reveal how it compares with other plant genes that regulate SA levels.

\section{N. edwardsonii is susceptible}

to TMV infection, in spite of the presence of the $N$ gene.

Papers that describe systemic TMV movement in $N$ genecontaining Nicotiana species generally fall into two categories.
In some cases, systemic movement reflects inactivation of targeted components of the defense signaling pathway (Delaney et al. 1994; Dinesh-Kumar and Baker 2000; Liu et al. 2002; Peart et al. 2002). However in other cases, TMV moves systemically in certain Nicotiana species such as N. edwardsonii, even in spite of the $N$ gene (Christie 1969; Dijkstra et al. 1977; Holmes 1954; Zaitlin 1962). The systemic movement of TMV in these plants and concomitant development of systemic necrosis indicates that the $N$ gene by itself may not prevent infection in some cases. Either the genetic background of the plant is lacking some defense component or the $N$ gene itself in these Nicotiana species is defective.

The differential response of $N$. edwardsonii and 'Columbia' to TMV inoculation allowed us to explore the genetic basis of systemic movement in the presence of the $N$ gene. Our nucleotide sequence evidence revealed that the coding sequence of the $N$ gene in $N$. edwardsonii matched that of $N$. glutinosa and 'Columbia' (Table 1). This indicates that the $N$ gene in $N$. edwardsonii is functional in recognition of TMV, but the genetic background of the original $N$. edwardsonii may compromise its defense response. In contrast, the genetic composition of 'Columbia' actually enhances the defense response of this plant to a range of pathogens, and presumably, TPRI would be one component of this enhanced defense response. TPRl may function in several ways to enhance mature plant resistance to TMV in 'Columbia'. The most pronounced effect involves upregulation of SA and PR proteins. Older 'Columbia' plants exhibited an enhanced level of conjugated SA, even when they were uninfected; this enhancement in conjugated SA levels became more pronounced after inoculation with TMV. One interpretation of this phenomenon is that older 'Columbia' plants may be primed to resist infections and this allows their defenses to respond even more rapidly after infection by an avirulent pathogen.

$\mathrm{SA}$ is an important signal in the induction of virus resistance, likely through the induction of an alternative oxidase (Chivasa et al. 1997; Murphy et al. 1999). This is consistent with enhanced resistance to TBSV and TNV in mature 'Columbia' plants. Further studies have shown that 'Columbia' exhibits enhanced resistance to infection by Pseudomonas tabaci and $P$. phaseolicola (data not shown), which would be consistent with a general enhancement of plant defenses due to elevated SA levels. The temporal induction of plant defenses in 'Columbia' may provide a new tool for studying plant defenses in Nicotiana. As microarrays for tobacco become available, it will be useful to examine which genes are specifically turned on in response to the temporal synthesis of the SA signal.

Another intriguing potential function of TPRI may involve the activation of senescence pathways in the leaf. In the original $N$. edwardsonii, virus infections in the petiole of inoculated leaves could be clearly delimited into necrotic and healthy sectors. In contrast, the petioles of inoculated 'Columbia' leaves would turn yellow, collapse, and abscise prematurely from the stem. The development of an abscission layer may physically prevent the virus from escaping through the petiole of an inoculated leaf to the rest of the plant. Leaf senescence and the HR are both forms of programmed cell death (Dangl et al. 2000). HR may hasten development of leaf senescence in 'Columbia' to stop pathogen infections.

\section{MATERIALS AND METHODS}

\section{Viruses and plants.}

The synthesis of $N$. edwardsonii is described in Christie (1969), whereas the synthesis of $N$. edwardsonii cv. Columbia is described in Cole and associates (2001). TMV and TBSV inocula were prepared from infected tobacco (N. tabacum) and 
$N$. benthamiana leaves, respectively, by grinding infected leaves in a mortar with a pestle and diluting to approximately $1: 20(\mathrm{wt} / \mathrm{vol})$ with inoculation buffer $(0.05 \mathrm{M}$ potassium phosphate buffer, $\mathrm{pH}$ 7.0). TNV inoculum was prepared similarly, except that dilution was 1:10 (wt/vol) with inoculation buffer, which was $0.1 \mathrm{M}$ potassium phosphate, $\mathrm{pH}$ 7.0. CaMV W260 inoculum for induction of PR-1 protein in N. edwardsonii was prepared as described in Cole and associates (2001). Inoculated leaves were lightly dusted with carborundum. The N. edwardsonii plants, 'Columbia' plants, and their hybrids were inoculated at either 35 or 60 days after planting (in case of TNV inoculations, 50, 80, and 90 days after planting). Seeds were scarified by soaking in $2 \%$ (vol/vol) $\mathrm{NaOCl}$ for $30 \mathrm{~min}$ prior to planting, as described by Burk (1957). Virus-inoculated plants were maintained in the greenhouse during the months of October to April. Greenhouse temperatures were continuously monitored with a datalogger (Campbell Scientific, Logan, UT, U.S.A.). Root tips of line 24 were prepared for cytological analysis according to Cole and associates (2001). Six plants produced mitotic metaphase chromosomes and two to ten cells per plant were counted. All cells contained 68 chromosomes.

\section{Sequencing of the $N$ gene \\ from Nicotiana species and hybrids.}

Total DNA was isolated from Nicotiana leaves by the procedure of Dellaporta and associates (1983). The $N$ gene was amplified in a series of overlapping PCR, and amplified DNA fragments were sequenced directly at the DNA sequencing core at the University of Missouri-Columbia. Primer sequences were derived from the published $N$-gene sequence (Whitham et al. 1994) and were synthesized by Integrated DNA Technologies (Coralville, IA, U.S.A.). All nucleotide differences were verified by determining the sequence of the affected region in both directions.

\section{Western blot analysis for PR-1 protein.}

Samples were prepared and electrophoresed as previously described (Király et al. 1999). Proteins were transferred to nitrocellulose membranes for $1.5 \mathrm{~h}$ at $300 \mathrm{~mA}$ (constant current) in $1 \times$ Towbin buffer ( $25 \mathrm{mM}$ Tris [pH 8.2], $192 \mathrm{mM}$ glycine, $0.1 \%$ [wt/vol] sodium dodecyl sulfate, $20 \%$ [vol/vol] methanol) (Towbin et al. 1979). The membranes were blocked overnight in blocking buffer (phosphate buffered saline [PBS; $\mathrm{pH} 7.4], 5 \%$ [wt/vol] nonfat dry milk, $1 \%$ [wt/vol] bovine serum albumin [BSA], $0.01 \%$ [vol/vol] Antifoam A) at $4^{\circ} \mathrm{C}$.

Membranes were incubated at room temperature for $1.5 \mathrm{~h}$ with a $1: 10,000$ dilution of anti-PR-1 IgG in antibody dilution buffer (PBS [pH 7.4], $0.05 \%$ [vol/vol] Tween 20, $0.2 \%$ [wt/vol] $\mathrm{BSA}$, and 2\% [wt/vol] polyvinylpyrrolidone, estimated molecular weight 40,000). This was followed by an incubation step using a 1:2,000 dilution of alkaline phosphatase-labeled rabbit-anti-mouse IgG (SBA, Birmingham, AL, U.S.A.). Protein bands were visualized by the addition of $10 \mathrm{ml}$ of alkaline phophatase color developer $(100 \mathrm{mM}$ Tris [pH 9.1], $100 \mathrm{mM} \mathrm{NaCl}, 5 \mathrm{mM} \mathrm{MgCl}_{2}, 0.4 \mathrm{mM}$ nitro blue tetrazolium chloride, $0.4 \mathrm{mM}$ 5-bromo-4-chloro-3-indolyl phosphate $p$-toluidine salt).

\section{Analysis of free and conjugated forms of salicylic acid.}

Free and conjugated (acid hydrolyzable) forms of SA were analyzed as described by Meuwly and Métraux (1993), with minor modifications. Ortho-anisic acid (2-methoxybenzoic acid, oANI) was used as an internal standard, in order to take account of losses during extraction, and para-hydroxybenzoic acid (pHBA) served as an extraction carrier. The initial extract was centrifuged at $8,000 \times g$ for $20 \mathrm{~min}$. Following resuspen- sion in $90 \%$ ( $\mathrm{vol} / \mathrm{vol})$ methanol, samples were recentrifuged as above. Supernatants were combined in a total volume of $2 \mathrm{ml}$, and the methanolic portion was evaporated at room temperature in a vacuum centrifuge. Trichloroacetic acid (1 $\mathrm{ml}$ of $5 \%$ [wt/vol]) was added to the remaining aqueous phase (approximately $0.4 \mathrm{ml}$ ), and the mixture was centrifuged at $8,000 \times g$ for $10 \mathrm{~min}$. The supernatant was gently partitioned twice (10 min each time) against $2.5 \mathrm{ml}$ of a $1: 1(\mathrm{vol} / \mathrm{vol})$ mixture of ethylacetate/cyclohexane. For determination of levels of free $\mathrm{SA}$, top organic layers containing the free phenolic portion were stored at $-20^{\circ} \mathrm{C}$. For determination of levels of conjugated SA, lower aqueous phases containing the bound phenolic portion were acid hydrolyzed with $\mathrm{HCl}$. The hydrolysis mixture was then centrifuged at $6,000 \times g$ for $10 \mathrm{~min}$, the supernatant was partitioned twice, as above, and the organic layers obtained were stored at $-20^{\circ} \mathrm{C}$.

Prior to HPLC (high performance liquid chromatography) analysis, organic phases were evaporated to dryness under vacuum and were resuspended in $1 \mathrm{ml}$ of HPLC starting mobile phase (discussed below). HPLC separation of SA and oANI was performed on a system equipped with a deactivated reversed-phase column as described by Meuwly and Métraux (1993). Column temperature was $40^{\circ} \mathrm{C}$, while samples were maintained at $10^{\circ} \mathrm{C}$. Elution began with an isocratic flow of $15 \%$ acetonitrile (ACN) in $25 \mathrm{mM} \mathrm{KH}_{2} \mathrm{PO}_{4}$ adjusted to $\mathrm{pH} 2.6$ (with HCL) for $1 \mathrm{~min}$. The concentration of ACN was then increased to $20 \%$ in 2 min and was kept isocratic for another $2 \mathrm{~min}$. The concentration of ACN was then raised successively to $60 \%$ in $15 \mathrm{~min}$ and to $100 \%$ in 2 min. The column was washed in $100 \%$ ACN for 5 min, prior to decreasing ACN concentration to $15 \%$ in $2 \mathrm{~min}$ and to equilibration for another $6 \mathrm{~min}$, before the subsequent sample was injected. Volume of injected samples was 20 and 40 $\mu$ for determination of free and conjugated SA, respectively. Levels of SA and oANI were quantified fluorometrically by changing excitation and emission wavelengths to optimize the signal for each compound, according to Meuwly and Métraux (1993).

\section{ACKNOWLEDGMENTS}

The authors thank S. Zhang for antibodies to PR-1 protein, D. Pinkerton for assistance with the photographs, and R. Nelson and W. Gassmann for comments on the manuscript. The help of G. Szalai in analyses of salicylic acid is gratefully acknowledged. This research was supported by the Missouri Agricultural Experiment Station, the Food for the 21st Century program at the University of Missouri, by U.S. Department of Agriculture/National Research Initiative Competitive grant number 9835303-6711, and by grants from the Hungarian Scientific Research Fund (OTKA TO43431 and F032397). L. Király was supported by a Bolyai János Research Fellowship.

\section{LITERATURE CITED}

Abbink, T. E. M., Tjernberg, P. A., Bol, J. F., and Linthorst, H. J. M. 1998. Tobacco mosaic virus helicase domain induces necrosis in $N$ gene-carrying tobacco in the absence of virus replication. Mol. Plant-Microbe Interact. 11:1242-1246.

Ahl, P., and Gianinazzi, S. 1982. b-Protein as a constitutive component in highly (TMV) resistant interspecific hybrids of Nicotiana glutinosa $\times$ Nicotiana debneyi. Plant Sci. Lett. 26:173-181.

Baker, B., Zambryski, P., Staskawicz, B., and Dinesh-Kumar, S. P. 1997. Signaling in plant-microbe interactions. Science 276:726-733.

Bol, J. F., Linthorst, H. J. M., and Cornelissen, B. J. C. 1990. Plant pathogenesis-related proteins induced by virus infection. Annu. Rev. Phytopathol. 28:113-138.

Bowling, S. A., Guo, A., Cao, H., Gordon, A. S., Klessig, D. F., and Dong, X. 1994. A mutation in Arabidopsis that leads to constitutive expression of systemic acquired resistance. Plant Cell 6:1845-1857.

Burk, L. G. 1957. Overcoming seed dormancy in Nicotiana. Agronomy J. 49:461. 
Carr, J. P., Beachy, R. N., and Klessig, D. F. 1989. Are the PR1 proteins of tobacco involved in genetically engineered resistance to TMV? Virology 169:470-473.

Chivasa, S. Murphy, A. M., Naylor, M., and Carr, J. P. 1997. Salicylic acid interferes with tobacco mosaic virus replication via a novel salicylhydroxamic acid-sensitive mechanism. Plant Cell 9:547-557.

Christie, S. R. 1969. Nicotiana hybrid developed as a host for plant viruses. Plant Dis. Rep. 53:939-941.

Christie, S. R., and Hall, D. W. 1979. A new hybrid species of Nicotiana (Solanaceae). Baileya 20:133-136.

Cole, A. B., Király, L., Ross, K., and Schoelz, J. E. 2001. Uncoupling resistance from cell death in the hypersensitive response of Nicotiana species to Cauliflower mosaic virus infection. Mol. Plant-Microbe. Interact. 14:31-41.

Cutt, J. R., Harpster, M. H., Dixon, D. C., Carr, J. P., Dunsmuir, P., and Klessig, D. F. 1989. Disease response to Tobacco mosaic virus in transgenic tobacco plants that constitutively express the pathogenesis-related PRIb gene. Virology 173:89-97.

Dangl, J. L., Dietrich, R. A., and Richberg, M. H. 1996. Death don't have no mercy: Cell death programs in plant-microbe interactions. Plant Cell 8:1793-1807.

Dangl, J. L., Dietrich, R. A., and Thomas, H. 2000. Senescence and programmed cell death. Pages 1044-1100 in: Biochemistry and Molecular Biology of Plants. B. Buchanan, W. Gruissem, and R. Jones, eds., American Society of Plant Biologists, Rockville, MD, U.S.A.

Delaney, T., Uknes, S., Vernooji, B., Friedrich, L., Weymann, K., Negrotto, D., Gaffney, T., Gut-Rella, M., Kessmann, H., Ward, E., and Ryals, J. 1994. A central role of salicylic acid in plant disease resistance. Science 266:1247-1250

Dellaporta, S. L., Wood, J. W., and Hicks, J. B. 1983. A plant DNA minipreparation: Version II. Plant Mol. Biol. Rep. 1:19-21.

Dietrich, R. A., Delaney, T. P., Uknes, S. J., Ward, E. R., Ryals, J. A., and Dangl, J. L. 1994. Arabidopsis mutants simulating disease resistance responses. Cell 77:565-577

Dijkstra, J., Bruin, G. C. A., Burgers, A. C., van Loon, L. C., Ritter, C., van de Sanden, P. A. C. M., and Wieringa-Brants, D. H. 1977. Systemic infection of some $\mathrm{N}$-gene-carrying Nicotiana species and cultivars after inoculation with Tobacco mosaic virus. Neth. J. Plant Pathol. 83:41-59.

Dinesh-Kumar, S. P., and Baker, B. J. 2000. Alternatively spliced $N$ resistance gene transcripts: Their possible role in tobacco mosaic virus resistance. Proc. Natl. Acad. Sci. U.S.A. 97:1908-1913.

Dixon, R. A., Harrison, M. J., and Lamb, C. J. 1994. Early events in the activation of plant defense responses. Annu. Rev. Phytopathol. 32:479501.

Dumas, E., and Gianinazzi, S. 1986. Pathogenesis-related (b) proteins do not play a central role in TMV localization in Nicotiana rustica. Phys. Mol. Plant Path. 11:69-76.

Erickson, F., Holzberg, S., Calderon-Urrea, A., Handley, V., Axtell, M., Corr, C., and Baker, B. 1999. The helicase domain of the TMV replicase proteins induces the $N$-mediated defence response in tobacco. Plant J. 18:67-75.

Fraser, R. S. S. 1981. Evidence for the occurrence of the 'pathogenesisrelated' proteins in leaves of healthy tobacco plants during flowering. Physiol. Plant Path. 11:69-76.

Greenberg, J. T., Guo, A., Klessig, D. F., and Ausubel, F. M. 1994. Programmed cell death in plants: A pathogen-triggered response activated coordinately with multiple defense functions. Cell 77:551-563.

Hennig, J., Malamy, J., Grynkiewicz, G., Indulski, J., and Klessig, D. F. 1993. Interconversion of the salicylic acid signal and its glucoside in tobacco. Plant J. 4:593-600.

Holmes, F. O. 1954. Inheritance of resistance to viral diseases in plants. Adv. Virus Res. 2:1-30.

Hugot, K., Aimé, S., Conrod, S., Poupet, A., and Galiana, E. 1999. Developmental regulated mechanisms affect the ability of a fungal pathogen to infect and colonize tobacco leaves. Plant J. 20:163-170.

Király, L., Cole, A. B., Bourque, J. E., and Schoelz, J. E. 1999. Systemic cell death is elicited by the interaction of a single gene in Nicotiana clevelandii and gene VI of cauliflower mosaic virus. Mol. PlantMicrobe Interact. 12:919-925.

Király, Z. Barna, B., Kecskés, A., and Fodor, J. 2002. Down-regulation of antioxidative capacity in a transgenic tobacco which fails to develop acquired resistance to necrotization caused by TMV. Free Radical Res. 36:981-991

Klessig, D. F., and Malamy, J. 1994. The salicylic acid signal in plants. Plant Mol. Biol. 26:1439-1458.

Leisner, S. M., Turgeon, R., and Howell, S. H. 1993. Effects of host plant development and genetic determinants on the long-distance movement of Cauliflower mosaic virus in Arabidopsis. Plant Cell 5:191-202.
Linthorst, H. J. M., Meuwissen, R. L. J., Kauffmann, S., and Bol, J. F. 1989. Constitutive expression of pathogenesis-related proteins PR-1, GRP, and PRS in tobacco has no effect on virus infection. Plant Cell $1: 285-291$.

Liu, Y., Schiff, M., Marathe, R., and Dinesh-Kumar, S. P. 2002. Tobacco Rarl, EDS1 and NPR1/NIM1-like genes are required for $N$-mediated resistance to Tobacco mosaic virus. Plant J. 30:415-429.

Lockhart, B. E., Menke, J., Dahal, G., and Olszewski, N. E. 2000. Characterization and genomic analysis of Tobacco vein clearing virus, a plant pararetrovirus that is transmitted vertically and related to sequences integrated in the host genome. J. Gen. Virol. 81:1579-1585.

Lotan, T., Ori, N., and Fluhr, R. 1989. Pathogenesis-related proteins are developmentally regulated in tobacco flowers. Plant Cell 1:881-887.

Malamy, J., Carr, J. P., Klessig, D. F., and Raskin, I. 1990. Salicylic acid: A likely endogenous signal in the resistance response of tobacco to viral infection. Science 250:1002-1004.

Malamy, J., Hennig, J., and Klessig, D. F. 1992. Temperature-dependent induction of salicylic acid and its conjugates during the resistance response to tobacco mosaic virus infection. Plant Cell 4:359-366.

Marathe, R., Anandalakshmi, R., Liu, Y., and Dinesh-Kumar, S. P. 2002. The tobacco mosaic virus resistance gene N. Mol. Plant Pathol. 3:167172.

McKinney, H. H., and Clayton, E. E. 1945. Genotype and temperature in relation to symptoms caused in Nicotiana by the mosaic virus. J. Heredity 36:323-331.

Meuwly, F., and Métraux, J.-P. 1993. Ortho-anisic acid as internal standard for the simultaneous quantitation of salicylic acid and its putative biosynthetic precursors in cucumber leaves. Anal. Biochem. 214:500505.

Mittler, R., Shulaev, V., Seskar, M., and Lam, E. 1996. Inhibition of programmed cell death in tobacco plants during pathogen-induced hypersensitive response at low oxygen pressure. Plant Cell 8:1991-2001.

Murphy, A. M., Chivasa, S., Singh, D. P., and Carr, J. P. 1999. Salicylic acid-induced resistance to viruses and other pathogens: A parting of the ways? Trends Plant Sci. 4:155-160.

Padgett, H. S., and Beachy, R. N. 1993. Analysis of a tobacco mosaic virus strain capable of overcoming $N$ gene-mediated resistance. Plant Cell 5:577-586

Peart, J. R., Cook, G. Feys, B. J., Parker, J. E., and Baulcombe, D. C. 2002. An EDS1 orthologue is required for $N$-mediated resistance against Tobacco mosaic virus. Plant J. 29:569-579.

Rate, D. M., Cuenca, J. V., Bowman, G. R., Guttman, D. S., and Greenberg, J. T. 1999. The gain-of function Arabidopsis acd6 mutant reveals novel regulation and function of the salicylic acid signaling pathway in controlling cell death, defenses, and cell growth. Plant Cell 11:1695-1708.

Ryals, J. A., Neuenschwander, U. H., Willits, M. G., Molina, A., Steiner, H. Y., and Hunt, M. D. 1996. Systemic acquired resistance. Plant Cell 8:1809-1819.

Samuel, G. 1931. Some experiments on inoculating methods with plant viruses, and on local lesions. Ann. Appl. Biol. 18:494-506.

Shah, J., Kachroo, P., and Klessig, D. F. 1999. The Arabidopsis ssi1 mutation restores pathogenesis-related gene expression in $n p r 1$ plants and renders defensin gene expression salicylic acid dependent. Plant Cell 11: 191-206.

Shirano, Y., Kachroo, P., Shah, J., and Klessig, D. F. 2002. A gain-of-function mutation in an Arabidopsis toll interleukin 1 receptor-nucleotide binding site-leucine-rich repeat type $R$ gene triggers defense responses and results in enhanced disease resistance. Plant Cell 14:3149-3162.

Sticher, L., Mauch-Mani, B., and Métraux, J.-P. 1997. Systemic acquired resistance. Annu. Rev. Phytopathol. 35:235-270.

Towbin, H., Staehlin, T., and Gordon, J. 1979. Electrophoretic transfer of proteins from polyacrylamide gels to nitrocellulose sheets: Procedure and some applications. Proc. Natl. Acad. Sci. U.S.A. 76:4350-4354.

Weststeijn, E. A. 1981. Lesion growth and virus localization in leaves of Nicotiana tabacum cv. Xanthi nc. after inoculation with Tobacco mosaic virus and incubation alternately at $22^{\circ} \mathrm{C}$ and $32^{\circ} \mathrm{C}$. Physiol. Plant Path. 18:357-368.

Whitham, S., Dinesh-Kumar, S. P., Choi, D., Heyl, R., Corr, C., and Baker, B. 1994. The product of the Tobacco mosaic virus resistance gene $N$ : similarity to toll and the interleukin-1 receptor. Cell 78:11011115

Yoshioka, K., Kachroo, P., Tsui, F., Sharma, S. B., Shah, J., and Klessig, D. F. 2001. Environmentally sensitive, SA-dependent defense responses in the cpr22 mutant of Arabidopsis. Plant J. 26, 447-459.

Zaitlin, M. 1962. Graft transmissibility of a systemic virus infection to a hypersensitive host-An interpretation. Phytopathology 52:1222-1223.

Zhang, S., and Klessig, D. F. 2001. MAPK cascade in plant defense signaling. Trends Plant Sci. 6:520-527. 